\title{
"El rostro de Córdoba". La industria como motivo del paisaje en la ciudad de Córdoba. Coyunturas y contrastes
}

\section{"The face of Córdoba". Industry as a landscape motif in the City of Córdoba. Conjunctures and contrast “}

\section{Santiago Llorens}

Laboratorio de Estudios Territoriales. Departamento de Geografía. Facultad de Filosofía y Humanidades. Universidad Nacional de Córdoba (UNC)

Argentina

sgollorens@gmail.com

\section{RESUMEN}

La aparición de infraestructura industrial no es suficiente para que se construya la idea de paisaje de ciudad industrial y menos aún para interpretar cuáles fueron los debates y sentidos en torno a esta. Intentaremos dilucidar estos aspectos estableciendo tres coyunturas en las que identificamos contrastes en la forma que la relación industria y ciudad es presentada como motivo del paisaje en Córdoba desde fines del siglo XIX hasta la década de 1960, momento en que se consolida la imagen de ciudad industrial. Los avances pretenden aportar a las indagaciones que lleva adelante el Grupo de Investigación en Industria, territorio y trabajo en Córdoba. Se argumenta que, a la relación entre ciudad material e imaginario, se debe articular la temporalidad propia de la idea de paisaje en Córdoba que establece una relación determinada -histórica y geográfica- entre imágenes y territorio material.

PALABRAS CLAVE: Idea de paisaje en Córdoba - imágenes de ciudad industrial imaginaciones geográficas - tensiones y/o disputas

\section{ABSTRACT}

The emergence of industrial infrastructure is not enough to make the idea of landscape industrial city is built and even less to interpret what were the debates and 
ways around this. Trying to elucidate these aspects, we establish three junctures in which we identify contrasts in the way in which the industry and city relationship is presented as a motif of the landscape in Córdoba from the end of the 19th century to the 1960s when the image of the industrial city was consolidated. It is argued that the relationship between the material city and the imaginary one must articulate the temporality proper to the idea of landscape in Córdoba, which establishes a certain relationship -historical and geographical- between images and material territory. The advances intend to contribute to the research carried out by the Research Group in Industry, territory and work in Córdoba.

KEY WORDS: Idea of landscape in Córdoba - images of an industrial city - geographical imaginations - tensions and / or disputes -

\section{INTRODUCCIÓN}

En 1965, la multinacional automotriz Ika se refería a un "nuevo rostro de Córdoba" en relación con la actividad industrial y con las transformaciones de la ciudad. En la actualidad sorprende que el imaginario de una Córdoba industrial, y en especial en su vinculación con el sector metalmecánico y automotriz, mantenga vigencia y fuerte presencia social incluso ante el proceso de reestructuración en el cual la industria pierde participación relativa frente a otros sectores de la economía cordobesa (Búffalo 2013; Búffalo, Carmona, García 2015). Esto lleva a considerar que si bien la historia del conjunto de narrativas espaciales -dentro de las cuales se encuentran las imágenes del paisaje- debe ser interpretada en relación a la reestructuración y a los giros de compresión espacio-temporal (Harvey 1990), los "imaginarios geográficos" (Zusman 2013), entre ellos los que refieren a la idea de paisaje, establecen relaciones no lineales con estos procesos. En términos analíticos, lo anterior implica no solo atender a la dislocación simbólica respecto a ciertos niveles de materialidad, y su autonomización -el imaginario de una ciudad industrial ante una imagen material que comienza a mostrar rasgos de ciudad posindustrial-, sino y dada la inquietud por el paisaje, a la temporalidad propia de la idea de paisaje en Córdoba que establece una determinada relación -histórica y geográfica- entre imágenes y territorio material. 


\section{Estudios sobre industria y territorio en Córdoba}

El presente trabajo pretende aportar a las indagaciones que desde hace 10 años lleva adelante el GIITT- Grupo de Investigación en Industria, territorio y trabajo- ${ }^{1}$. Este grupo ha centrado su análisis en el comportamiento del sector industrial en Córdoba en el contexto de reestructuración productiva y sus implicancias en el territorio a distintas escalas. Los trabajos observan cómo las industrias tendiendo a formas más flexibles, transforman sus patrones de acumulación y localización lo cual se refleja en la red urbana y en la configuración de las propias ciudades. Reconociendo las respuestas diferenciadas a este contexto se ha indagado el sector metalmecánico (Búffalo, 2013), automotriz (Tomadoni, Búffalo, Berti; 2009), de maquinaria agrícola (Astegiano, 2018), entre otras. El énfasis que se coloca en el proceso de reestructuración y sus aspectos materiales parece dejar poco espacio para indagar la relación entre imaginarios, imágenes (visuales, literarias o técnicas) y el paisaje. Sin embargo, la aparente contradicción entre este proceso y la simultánea puesta en movimiento por diversos actores -entre ellos el Estado provincial- de una imagen de ciudad industrial para Córdoba, es lo que ha llevado desde el año 2019 a indagar los "imaginarios geográficos" (Zusman, 2013), y en especial las controversias en diversas coyunturas históricas respecto a la industria como motivo del paisaje.

Se presenta aquí una esquematización que podrá ser revisada según emergentes del proceso de investigación. Establecemos tres coyunturas en las que identificamos contrastes en las formas en que la relación industria y ciudad es presentada en el paisaje en Córdoba: a) un primer encuadre entre fines del siglo XIX y primera década del XX que refiere a los orígenes de la industria en Córdoba en la que el esfuerzo se dirige a presentar el paisaje de una ciudad moderna e industrial; b) un segundo encuadre que se consolida en el contexto del centenario y se mantiene hasta mediados del siglo donde lo industrial pierde la relevancia como motivo del paisaje y se prefieren motivos religiosos y/o tradicionales para mostrar a Córdoba, y; c) un encuadre en el que confluyen de la mano de las políticas desarrollistas diversos actores sociales para convertir a la industria en "lugar común" (Silvestri, 2011) del

\footnotetext{
${ }^{1}$ GIITT- Grupo de Investigación en Industria, territorio y trabajo-. Laboratorio de Estudios Territoriales. Facultad de Filosofía y Humanidades. Universidad Nacional de Córdoba.
} 
paisaje urbano cordobés. Encuadre que rápidamente evidenciará contradicciones y conflictos.

\section{Paisaje e industria}

El argumento evidente que surge de los desplazamientos entre estas tres coyunturas es que la aparición de infraestructura industrial en el orden de lo sensible -visual- o su mero ensamblaje como morfología (del paisaje), no es suficiente para que se construya la idea de paisaje de ciudad industrial y menos aún para interpretar cuáles fueron los debates y sentidos sobre estos.

Muchos trabajos referidos al paisaje presentan un interés por las transiciones económicas y la dinámica por la cual el capital crea y recrea un "paisaje geográfico (un entorno construido y culturas locales)" que sirven a su reproducción (Harvey 2017: 79). De la mano del materialismo cultural se señalará, al igual que sucede con las mercancías u otros productos culturales, la función ideológica de dichos paisajes geográficos. En esta línea, sin perder de vista dichas transiciones las indagaciones se aproximaron a las transformaciones en las "formaciones sociales" con la intención de dar mayor énfasis a las dimensiones sociales y culturales sin caer en mecanicismos o determinismos económicos (Cosgrove, 1998, Williams, 2002). Estos últimos se han centrado en los registros visuales o literarios involucrados en la construcción de una mirada en la que el entorno se transformaba en paisaje. Mirada que respondía a una razón de control y a un orden social e histórico preciso donde se dirimían las luchas por la propiedad. Con algunos desplazamientos teóricos, es de interés la ampliación contemporánea de estos trabajos hacia la pregunta por la articulación del paisaje con la experiencia de las modernidades y los occidentes, y en especial aquellos que se concentran en contextos periféricos (Navarro Floria, 2007; Zusman, 2013).

Marguelichi (2015), al indagar en la relación paisaje e industria señala la dificultad que existió para articularlos en tanto parecen contradecirse en sus términos. Es probable que como señala Silvestri, la novedad tecnológica de la industria deba naturalizarse para convertirse en paisaje. Sin embargo, lo propio -lo veremos en Córdoba-, es que deben realizarse por algún margen de tiempo diversas operaciones sociales, políticas y técnicas, para que la infraestructura industrial que va emergiendo en la ciudad sea transformada en motivo del paisaje y se construya 
cierto acuerdo sobre los sentidos que pretenden comunicar. Por último, es fundamental reconocer, que la relación entre un paisaje -material y visual- y su imaginario social posee "una vida (múltiples comienzos, transformaciones de sentido, exangües sobrevidas, resurgimientos, desaparición)” (Silvestri, 2012: 41).

El concepto de imaginario traído aquí coincide con la conceptualización de paisaje presentada previamente, al señalar que más allá de la presencia física-morfológica (de un Real en términos filosóficos), o una "imagen de", nos encontramos ante una creación (García Canclini, 2007; Zusman, 2013). Para Cosgrove, "la imaginación lleva a que la información captada a través de los sentidos no sea reproducida de forma mimética sino "metamorfoseada" generando nuevos significados" (Zusman, 2013: 59). Aquí, las imaginaciones geográficas no estarían asociadas solo a los procesos de dominación sino también a procesos creativos y a prácticas que pueden transformar la geografía material para construir "un mundo más habitable" (Zusman, 2013: 63 parafraseando a Ricoeur).

\section{MATERIALES Y MÉTODOS}

El análisis se centra en tres coyunturas en las que identificamos contrastes en las formas en que la relación industria y ciudad es presentada en la idea de paisaje en Córdoba. EI GIITT nombrado previamente, cuenta de una amplia base de datos cuantitativos (registros industriales provinciales, información estadística pública) cualitativa, georeferenciada y actualizada de las industrias de la ciudad de Córdoba, producto de 10 años de trabajo. Para la presente línea se desarrolla desde una estrategia cualitativa situada en las propuestas críticas de la geografía histórica siguiendo los enfoques metodológicos de Driver (2013) y Zusman (2013). Se trabaja fundamentalmente con fuentes documentales y material de archivo de diversos repositorios. Se reconoce que las lecturas de las fuentes están mediadas tanto por las posturas teóricas que orientan la investigación como las vivencias del presente (Zusman, 2013). Los registros de narrativas e imágenes de archivos y entrevistas complementarán la base de datos del Grupo de Investigación. 


\section{Del ensueño teológico al ensueño industrial}

“...cualquier escéptico del litoral nos va a decir que en Córdoba ha reemplazado al ensueño teológico el ensueño industrial!" (Amado J. Ceballos -Ashaverus- 1897:303)

Con estas impresiones, Amado J. Ceballos-cordobés, corresponsal viajero, militante del modernismo, publicaba durante la década de 1890 en el periódico La Nación una serie de "notas de viaje" luego recopiladas en un texto que da a llamar "Tierra Adentro", prologado nada menos que por el poeta modernista Rubén Darío. En ellas se tensionaban dos imágenes de la ciudad que -como polos dialécticos- se contraponían desde la llegada del ferrocarril a Córdoba y que se han ido resolviendo de manera singular hasta la actualidad: la ciudad enclaustrada, de campanarios y procesiones religiosas versus la ciudad abierta, moderna e industrial. Se afirmaba que en poco tiempo de la mano de la industria Córdoba podría "ser convertida en la ciudad fabril por excelencia de la República" (Amado J. Ceballos -Ashaverus1897:303).

Respecto a la industria en Córdoba ${ }^{2}$ del período, según Ansaldi, la "transición" del artesanado a la manufactura y la fábrica se consolida hacia 1880 , centrada en la alimentación, el calzado, construcción de productos químicos y energía eléctrica, y, si bien moderada en términos cuantitativos, se caracterizará por el nivel relativamente alto de tecnología empleada en estos sectores de punta (Ansaldi 2000: 72). Hacia 1905, la "Geografía de Córdoba" de Río y Achaval (cuya redacción fue solicitada por la Provincia) señalaba que, salvo las excepciones nombradas previamente, "las industrias permanecen todavía en estado embrionario" (Río y Achaval 1905 Vol II: 277-278).

Esta situación embrionaria es interpretada con optimismo en tanto una serie de condiciones materiales permitirían el despliegue de una pronta Córdoba industrial: la "liberal" legislación provincial, gran número de trabajadores migrantes europeos presentados como expresión de la vitalidad e industria de la ciudad, la energía

\footnotetext{
${ }^{2}$ La población de la ciudad pasaba de 34.458 habitantes en 1869, 54.763 en 1895, y 134.935 en 1914. (Primer Censo Nacional de Población de 1869)
} 
hidroeléctrica, combustible a bajo precio de sus bosques, materias primas para las industrias alimenticias y las industria del vestido y "la situación de Córdoba en el centro de la República con cuyas extremidades más distantes está ya unida por líneas de ferrocarril..." (Río y Achaval, 1905 Vol II: 277)

Si en términos materiales la industrialización del período resultaba restringida y frágil, lo relevante es que Córdoba comienza a ser mostrada como ciudad moderna e industrial. Esta industria "con su carácter cualitativo", "se mantiene grosso modo hasta las transformaciones sustantivas iniciadas en 1946..." (Ansaldi 2000: 278), pero con posterioridad veremos que las imágenes arquetípicas para definir el paisaje cordobés se distancian de las formas industriales para recaer en su aspectos telúricos y bucólicos.

\section{Córdoba azul: ciudad de campanas y la cuestión del equilibrio}

Si bien no debemos olvidar el proceso descrito en el apartado anterior, distintas investigaciones señalan que la industria es uno de los factores estructurales de la economía urbana desde el año 1927 con la localización de la primera Fábrica Militar de Aviones en Córdoba, hito que sirve posteriormente para atraer a la industria automotriz en 1952 (Búffalo, 2013; Cecchetto, 1988). Con la instalación de dicha fábrica, la ciudad se extendió hacia el oeste sobre la línea del camino a Malagueño hoy Avenida Fuerza Aérea- en barrios que fueron paulatinamente ocupados por obreros fabriles mientras los habitantes de la ciudad se incrementaban de 134.935 en 1914 a 368.828 en 1947.

A las industrias "tradicionales" del periodo anterior -harinas, cueros, cerveza, cementos- se suman entonces, las más dinámicas como las desarrolladas en la Fábrica Militar de Aviones y los talleres del Ferrocarril del Estado localizados en el noreste de la ciudad ${ }^{3}$, absorbiendo este sector nada menos que el $37 \%$ de la mano

\footnotetext{
${ }^{3}$ La FMA abre sus puertas en 1927 durante la presidencia del radical Marcelo T. Alvear. Hacia mediados de la década de 1940 en la presidencia de Juan D. Perón se expande conformando el complejo fabril I.A.M.E (Industrias Aeronáuticas y Mecánicas del Estado) diversificando su producción a utilitarios, tractores, motocicletas, bicicletas, etc. y empleando a más de 9000 obreros. Por su parte los Talleres del Ferrocarril de las líneas británicas creados para el mantenimiento del material rodante fueron nacionalizados en 1948 llegando a ocupar a 4000 obreros según estimaciones.
} 
de obra empleada (Pianetto, 2017: 226). En este marco, la progresista gobernación de Sabattini (1936-1940), emprende importantes políticas sociales y de obras públicas. Sin embargo, frente a la selección del algún motivo industrial como rasgo distintivo del paisaje urbano, se afirma la imagen de "docta ciudad" y el "tradicional perfil de centro comercial redistribuidor" (Pianetto,2017: 226).

En el mismo año en que se inician las actividades de la Fábrica Militar de Aviones, podemos encontrar dos registros que parecen tensionar el "ensueño industrial" de la coyuntura analizada previamente. Por un lado, un importante acto de gestión pública urbana al presentarse el primer "Plan regulador y de extensión de la ciudad de Córdoba". Este era solicitado por el demócrata conservador intendente Emilio Olmos -con el respaldo del gobernador Ramón Cárcano- al paisajista-urbanista de Buenos Aires, Benito Carrasco ${ }^{4}$. El impactante plano de la ciudad daba cuenta de aspiraciones modernas puestas en juego en una ciudad en aceleradas transformaciones, pero el matiz político y social delinearía la forma en que este se sitúa localmente ${ }^{5}$.

A fines de 1927, cuando Carrasco presenta su proyecto, el modo de aparecer de la ciudad será novedoso, en un plano visualmente impactante y con profundas diferencias respecto a la material ciudad, Figura 1. Por primera vez Córdoba es parte de un dispositivo -un Plan regulador- que permitía una mirada sinóptica y ciertas operaciones técnicas de conjunto. Se propuso un "sistema mixto" que combina el "sistema rectangular combinado con el radial y el pintoresco" que, según el paisajista, era el que "se adapta a nuestro medio ambiente". Se articuló por tanto, de manera ecléctica, la herencia local del damero, los lineamientos del movimiento citybeautiful y las ideas de calles irregulares de la ciudad jardín (Garden City) de

\footnotetext{
${ }^{4}$ AHMC Libro actas de sesiones 1926 №6 diciembre 1926 ff. 164

${ }_{5}$ Al respecto, reconociendo que el término puede generar desacuerdos, se denomina como conservadoras a esta expresión de fuerzas políticas siguiendo a Moyano (2012). Gorelik, al analizar en similar período los debates en torno al Proyecto Orgánico de Buenos Aires y las expresiones políticas con mayor presencia de fuerzas políticas progresistas que Córdoba-, se verá obligado a concebir el paradojal término de "modernización reactiva" para dichas operaciones urbanas (2010: 315). La particularidad de Córdoba es que a diferencia de otras provincias, el éxito electoral del Partido Demócrata -continuación del régimen oligárquico establecido por el Partido Autonomista Nacional- se mantuvo con breves interrupciones hasta 1928 en lo que respecta a la gobernación.
} 
Howard. Entre los aspectos relevantes en la "ciudad vieja" se establecían ensanche de calles, las barrancas que rodeaban la ciudad serían transformadas en pintoresquistas "barrios jardines" y se constituía un extenso Boulevard de Circunvalación que delimitaba la expansión de la ciudad a 6000 hectáreas.

No solo es significativo que en la solicitud elevada por el ejecutivo municipal no existiera mención relevante respecto a la dimensión industrial, sino que tampoco en la gran expansión proyectada, solo una cifra estimada en 300 hectáreas correspondía a la localización de industrias ${ }^{6}$.

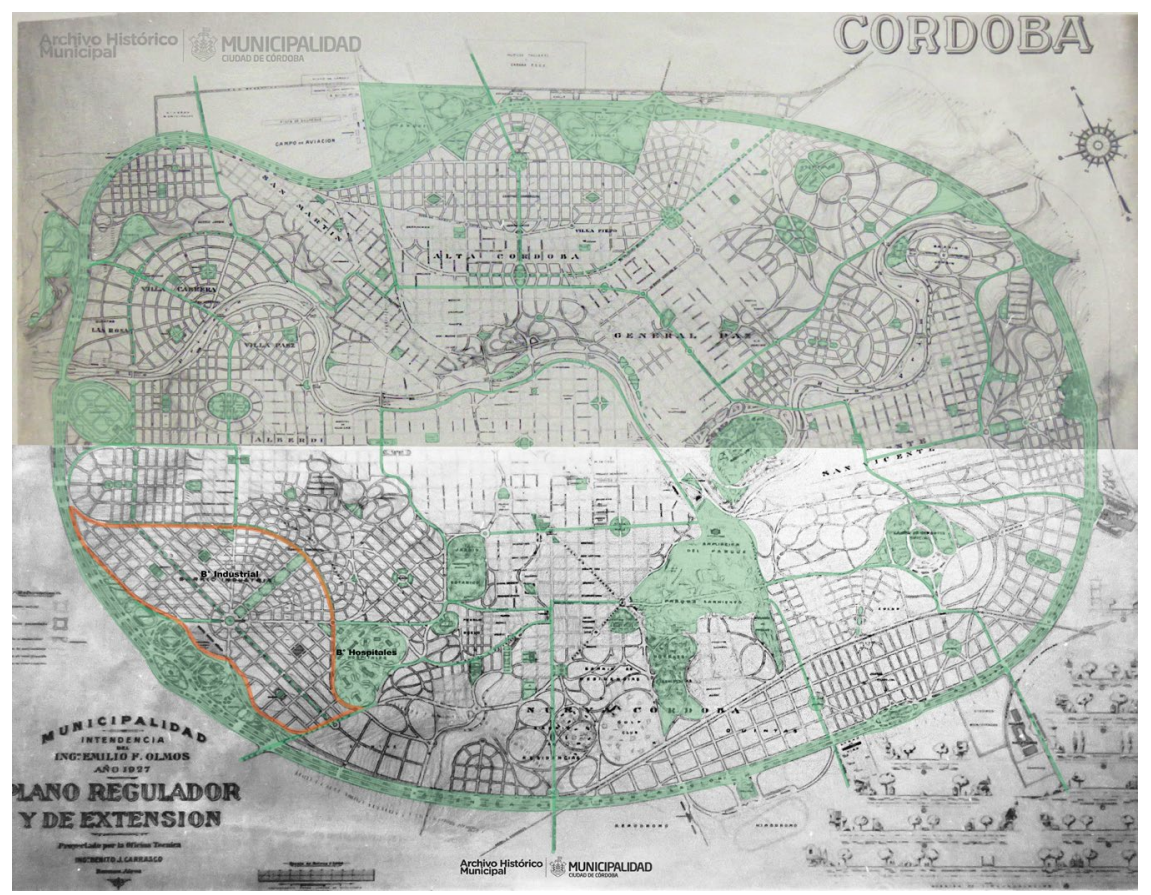

Figura 1: Córdoba. Plan regulador y de extensión estudiado por Benito Carrasco (1927).

Fuente: Inv. 2403 e Inv. 2404. AHMC. (Se señala Barrio Industrial a los fines del presente artículo)

${ }^{6}$ Plan Carrasco 1927 pp. 33 
Reconociendo que por razones históricas y de matriz económica los "planes reguladores" en Argentina no respondían en primera medida a la inquietud de mitigar las consecuencias indeseables del proceso de industrialización, podemos señalar que incluso con sus ideas modernizadoras, se mostraba que a la estrecha elite cordobesa le costaba ir más allá de sus intereses acomodaticios y de su vinculación al negocio inmobiliario urbano que tanto rédito le había dado en décadas anteriores para colocar a la industria como objetivo del Plan 7 .

El otro registro, es el reconocido Álbum de la Provincia de Córdoba (1927). En sus más de 850 páginas de grandes dimensiones apaisadas, la obra ofrece a través de fragmentos de descripciones científicas, literarias, pictóricas y fotográficas del territorio, un telón de fondo que ratifica la mirada pintoresca. En el compendio, las imágenes y/o publicidades de la actividad industrial cuidan celosamente preservar un "equilibrio" de conjunto que reafirme la personalidad religiosa y la mirada pintoresca de sierras y ciudad. Al tratar la ciudad, en la predilección por las "casas" y "pórticos" de la colonial arquitectura, se afirma el reconocimiento a una sociedad patricia acompañada por listas de "figuras ilustres" que coinciden con las autodenominadas familias de la "aristocracia" cordobesa, en una ciudad prácticamente no contaminada por otros contingentes sociales.

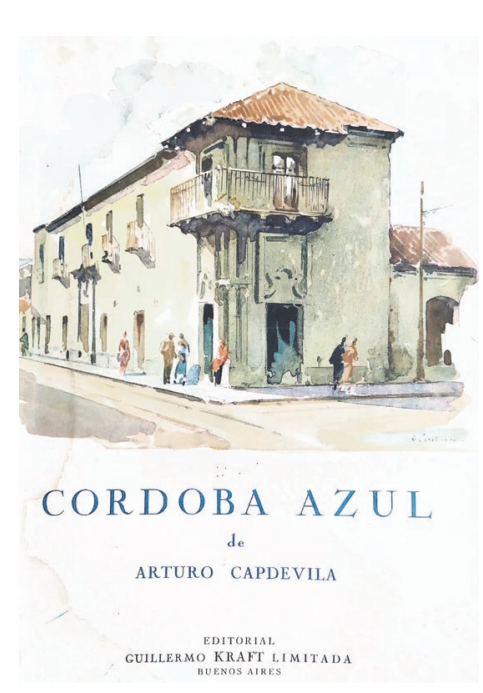

Figura 2: Capdevila (1949) Portada, Córdoba Azul

En un periodo bastante tardío, el afamado poeta Arturo Capdevila en una obra literaria denominada "Córdoba Azul", la Figura 2-reeditada en tres oportunidades

\footnotetext{
${ }^{7}$ En oficialismo como oposición no existe discusión dé relevancia referida al sector industrial en dicho Plan, las mismas se concentran exclusivamente en proyectos de urbanización y/o ensanches que tocaban intereses individuales y en parte especulativos.
} 
entre 1940 y 1949- selecciona para su portada la imagen de la "casa" de quien fuera Gobernador intendente de la Córdoba del Tucumán y luego Virrey del Río de la Plata Rafael de Sobremonte y define a Córdoba con la imagen tantas veces repetida de "ciudad de las campanas" en referencia directa a su espíritu tradicional y clerical. Tanto en las imágenes literarias y pictóricas del paisaje urbano se encuentra una ausencia completa del motivo industrial.

¿Cómo interpretar este anacronismo cuando la industria de fines del siglo XIX trabajada en el apartado anterior- y el proyecto de la Fábrica Militar de Aviones de 1927 se encuentran completamente materializados en la morfología del paisaje urbano? La respuesta debemos buscarla en las disquisiciones sobre la "identidad nacional", aparentemente imposibles de escindir hasta entrada la década de 1940 de la idea de paisaje. Son los movimientos nacionalistas del contexto del centenario - 1910 y 1916- los que consolidan la visión idealizada de Córdoba como expresión del interior profundo y auténtico, apelando a una geografía que en su particularidad podía aportar a la identidad y ser nacional frente a fuerzas "cosmopolitas" y "desintegradoras".

El motivo de la industria no solo no armonizaba con el paisaje pintoresco que servía al imaginario del interior profundo y auténtico señalado para Córdoba, sino que traía consigo otro riesgo. Si en el período anterior, se celebraba las "multitudes trabajadoras" migrantes, en este período de crisis económica y política, diversos sectores inmigrantes y obreros serían identificados con aquellas "fuerzas desintegradoras". Así, aparentemente, siquiera los discursos del industrialismo impulsados por el gobierno de Sabattini y posteriormente por el peronismo hubieran podido torcer de manera definitiva la imagen de "la Sevilla Americana" (Boixados, 2010: 40), de "docta ciudad" y del pintoresco y parroquial paisaje cordobés.

\section{Contrapuntos en el paisaje de la ciudad desarrollista}

Podemos sugerir que es avanzada la década de 1950, con las olas desarrollistas, cuando la industria se coloca como motivo central para presentar el paisaje de la ciudad de Córdoba. Si anteriormente la dimensión industrial era ambigua, para el año 1963 Alfredo Terzaga en su Geografía de Córdoba afirma sin ninguna vacilación que "la formación de una conciencia industrial ha sido estimulada en Córdoba por 
las empresas, los sindicatos obreros y el Estado provincial" (1963: 248) a través de diversas acciones, Figura 3.

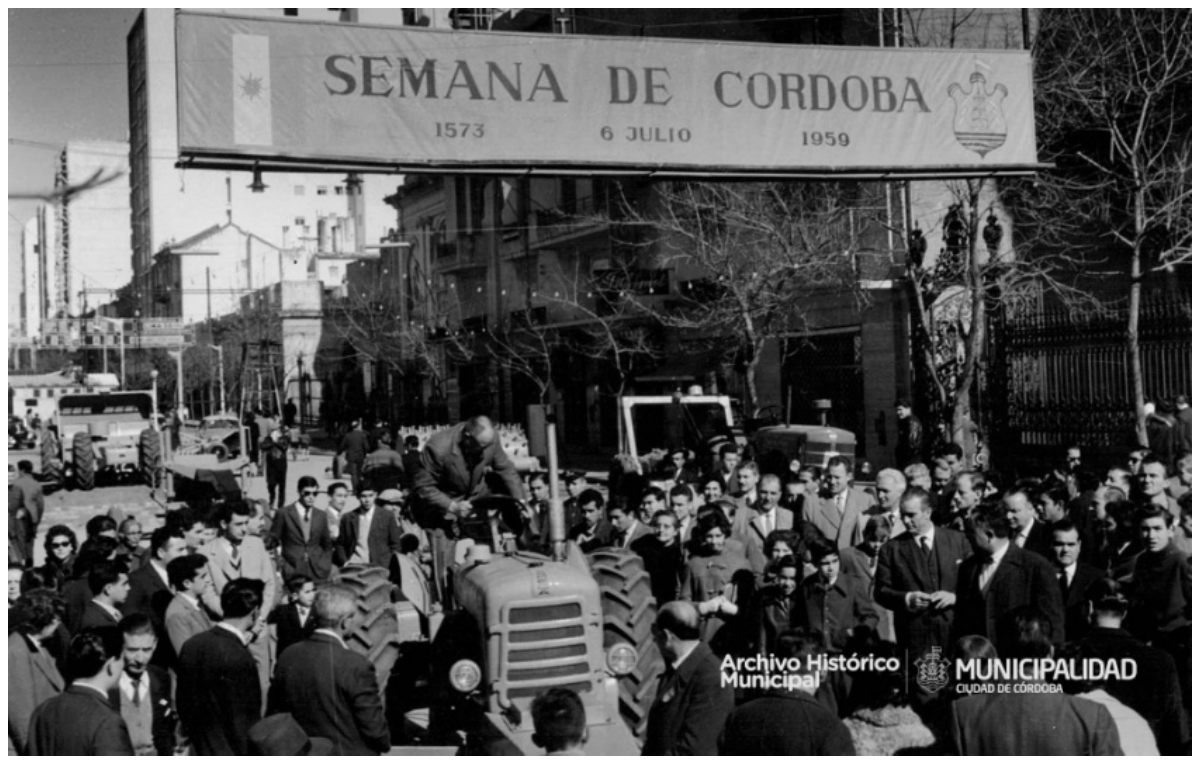

Figura 3. Tractor Someca (Fiat-Concord) producido en la Planta de Ferreira exhibido en Celebración de la Semana de Córdoba organizada Municipalidad de Córdoba (1959). AHMC Inventario 741 Frente

La profundización del proceso de sustitución de importaciones implicó importantes transformaciones para la ciudad de Córdoba. La Fábrica Militar de Aviones y la posterior localización -1952- de las Industrias Aeronáuticas y Mecánicas del Estado (IAME) (luego DINFIA) "sentarán las bases del knowhow para atraer en los años posteriores la localización de la industria automotriz, autopartista y el desarrollo posterior de la industria metalmecánica" (Buffalo, 2013: 107). A la expansión propia de las adyacencias de los barrios tradicionales se agregó hacia el sur y sureste de la ciudad un cinturón de urbanizaciones que se desarrolló en el anillo exterior "generando un proceso de intensa subdivisión de la tierra suburbana" (Cecchetto, 1988: 39). El consecuente crecimiento del empleo industrial incentivó una marcada presencia de flujos migratorios y el crecimiento de la ciudad ${ }^{8}$. Ante el escenario

\footnotetext{
${ }^{8}$ Cecchetto señala que la producción manufacturera quintuplicó su valor entre 1954 y 1962, aumentando el consumo de energía industrial un $320 \%$ construyéndose más de $500.000 \mathrm{~m} 2$ para el funcionamiento
} 
anterior, Cecchetto no duda en afirmar que la radicación de las multinacionales Fiat y las Industrias Kaiser Argentina (Ika, luego Ika-Renault), y el desarrollo del sector autopartista asociado, implicaron "la base material de transformación de la estructura social y urbana de la ciudad" (1988).

\section{"El nuevo rostro de Córdoba"}

A las acciones del Estado con sus leyes y promociones de los ' $50^{9} \mathrm{y}$ las posteriores políticas desarrollistas de Frondizi (1958-1962), se acoplaron las acciones de las empresas multinacionales, las cuales abonaron por medio de diversas estrategias a un determinado modelo e imagen de ciudad industrial.

Para 1965, la multinacional Ika, conmemorando los diez años de su instalación en Córdoba en una publicación formato libro, titula una de sus notas "El nuevo rostro de Córdoba" y argumenta que existía "una correlación ostensible" entre el crecimiento edilicio "y el nuevo pulso de la ciudad, con la instalación de la industria automotriz en Córdoba” (Ika 1965: 22).

En esta "correlación ostensible", el "nuevo rostro de Córdoba" y la idea de paisaje industrial que suponía, fue quedando completamente ligada al "imaginario de modernización y progreso" de las multinacionales (Rocca 2017), a tal punto que se hacía presente cierto optimismo social - más relevante aún si se considera la proscripción de la principal fuerza política de masas- respecto a la posibilidad de alcanzar el progreso y la modernización de la mano de dichas industrias. Parte de este encuentro entre las multinacionales y la ciudad, tenía que ver con las estrategias desarrolladas por las propias firmas en campos que trascendían lo industrial y económico para situarse en las disputas del campo cultural.

\footnotetext{
del sector. El aumento del empleo industrial transformó a la ciudad en polo de atracción de un flujo considerable de mano de obra, determinando que la población aumentara en un 52\% entre 1947 y 1960. El sector automotriz y metalmecánico desplazó a un segundo plano al tradicional sector industrial de alimentos y bebidas (Cecchetto 1988).

9 Acompañaban a este proceso la Ley de Radicación de Capitales Extranjeros (1953) del gobierno peronista, y la de Inversiones Extranjeras (1958) y de Promoción Industrial (1959) durante el gobierno de Frondizi.
} 
Aquí fue paradigmático la modalidad desplegada por la nombrada automotriz norteamericana y su profesional División de Relaciones Públicas. La actividad estrictamente fabril era acompañaba con la organización de cuidadosas publicaciones dirigidas a un público amplio como la revista Gacetika, el patrocinio de importantes exposiciones artísticas ${ }^{10}$ y eventos diversos: deportivos, festejos, donaciones, visitas a las plantas, etc. Analizando estas estrategias, Tedesco (2013) remarca el papel de la automotriz estadounidense en la construcción de una nueva imagen de ciudad. Rocca (2017) observa específicamente el rol de esta multinacional en relación a las disputas en el campo del arte y las transformaciones políticas y sociales de la época, mientras que Malecki encuentra su vinculación con la presencia de nuevos imaginarios urbanos (2015).

Un aspecto relevante es que más allá de las contradicciones materiales, la multinacional tuvo éxito, al construir una idea de paisaje en Córdoba en la que la industria no implicaba una ruptura dramática, sino que podía integrarse y dinamizar a "una ciudad conocida por su arraigada historia y tradición" (Tedesco, 2013: 190), y cimentar un futuro deseable desde esa relación, Figura 4.

En un contexto caracterizado por la Guerra Fría y las tensiones propias del orden bipolar, la empresa no solo construyó una idea singular de paisaje industrial para la ciudad de Córdoba, sino que a otras escalas resultó "un eslabón eficiente de la política exterior norteamericana" en la mantención de la hegemonía de EEUU en las relaciones internacionales (Rocca, 2017:344). Proceso que fue acelerado y principalmente contradictorio, contradicciones que según los actores el propio velo del moderno paisaje urbano de Córdoba ocluía, o bien, como veremos, explicitaba y potenciaba.

\footnotetext{
${ }^{10}$ Entre estas se destacaron los cuatro Salones de Arte (entre 1958 y 1961) y las tres Bienales (entre 1962 y 1966) patrocinadas por la automotriz norteamericana y cuya particularidad residía en que convocaba exclusivamente artistas latinoamericanos (Rocca, 2017).
} 


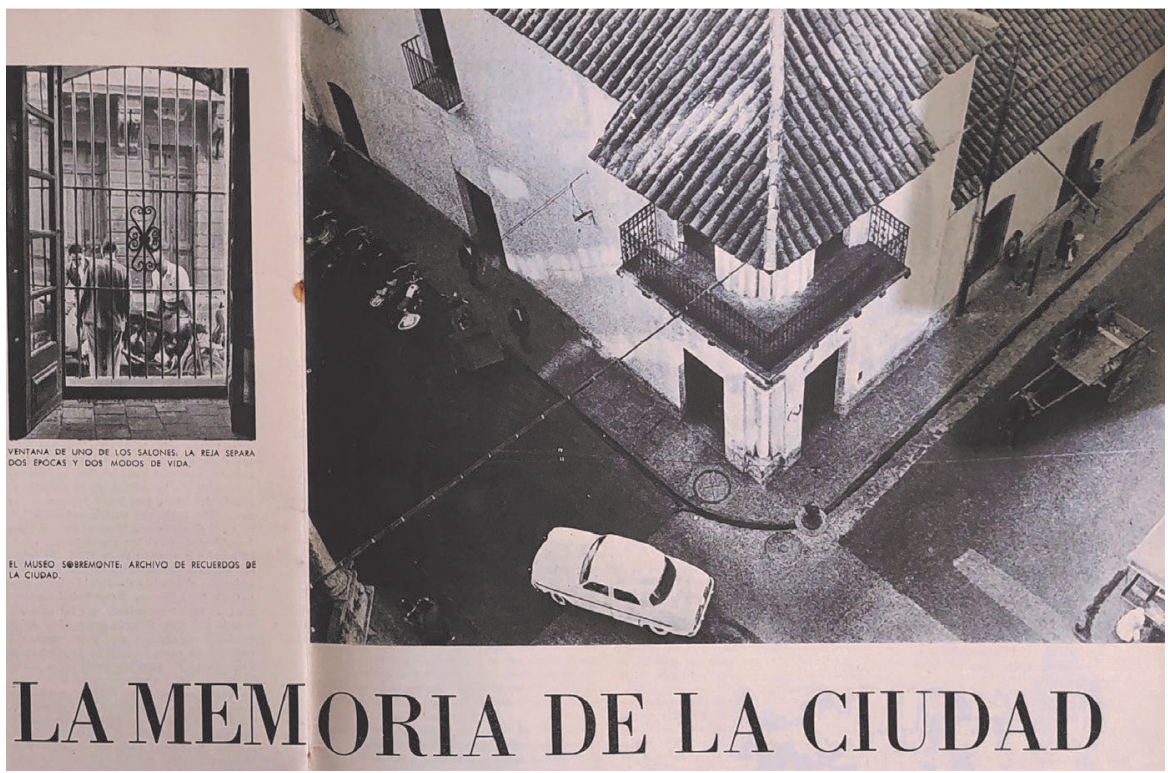

Figura 4. Gacetika 1965 Año VIII № 76 pp. 24,25. (Nota del autor. Observar que la edificación corresponde a la imagen en Figura 2 pero invirtiendo la toma a media altura por el vuelo de pájaro) En Tedesco (2013) se selecciona esta imagen, pero en un análisis algo diferente.

\section{Córdoba para la "patria socialista"}

En 1973, en un recordado acto en Córdoba, nacía el Movimiento Sindical de Base, entre cuyos impulsores se encontraba el PRT (Partido Revolucionario de los Trabajadores). El orador principal y líder del Cordobazo Agustín Tosco -quien formó parte del FAS (Frente Antiimperialista por el Socialismo) pero no del PRT-, en medio de consignas clasistas y revolucionarias de miles de personas, interpelaba aquellas imágenes de las multinacionales, manifestando que "vamos a hacer de Córdoba el corazón de la patria socialista" ${ }^{11}$. El paisaje de la ciudad se convertía en la expresión del poder imperialista y dialécticamente en su negación.

\footnotetext{
${ }^{11}$ Sobre el acto y las organizaciones presentes ver El combatiente Año VI. № 82 Julio de 1973 pp 9-11. Según este las palabras de Tosco fueron "por la liberación nacional y social de Argentina y América latina y por la sociedad socialista".
} 
El contraste con la discursividad que vimos en el apartado previo lleva a preguntarse en cómo descifraban y qué paisajes construían de la industria y de la ciudad estos actores sociales. Para ensayar una respuesta a ese interrogante analizo la interpretación que realizara un partido político de base marxista-leninista PRT, que fue ganando presencia en el sindicalismo clasista del período, y que en 1970 formó el ERP (Ejército Revolucionario del Pueblo) como brazo armado del partido.

Atendiendo al papel que los movimientos políticos autodenominados de "vanguardia" otorgaban a la "propaganda" -igual lo hacían las multinacionales-, resulta de interés analizar las imaginarias geográficas y paisajes que interpretaban y producían- desde sus órganos de difusión ${ }^{12}$ en una definición contrahegemónica antiimperialista, clasista, antidictatorial-.

Por motivos históricos y teórico-políticos no debe suponerse que paisaje e imaginarios geográficos responden a categorías de los propios actores o "nativas". De hecho, mi interpretación es que, desde su "socialismo científico", se revelan y objetivan las tensiones y límites del paisaje en tanto concepto -o al menos de ciertas ideas de paisaje-. Por un lado, ese paisaje de la industria y de la ciudad construido por las multinacionales, no podía ser visto por este movimiento sino dialécticamente, como la base material (Mitchell D., 2008) y el "sueño del imperio" (Mitchell W.J.T, 2002). Poder material y tangible de las corporaciones multinacionales modelando el paisaje industrial, urbano y del trabajo que estaría adquiriendo formas más dramáticas y contradictorias que en los países centrales. Por otro lado, y creemos que por sus consecuencias esto es aún más relevante, como había observado perspicazmente Cosgrove (1998), aquello que se colocaba en tanto paisaje, desde el lente del materialismo histórico, manifestaba la obliteración de la historia y del trabajo. Por lo tanto, no había camino a través de este objeto estetizado y completamente antagónico al trabajo y la praxis, para convertirlo en mediación práctica de una praxis política-revolucionaria.

\footnotetext{
${ }^{12}$ El Combatiente №76, marzo 1973. En Córdoba funcionaría desde el año 1973 una de las dos imprentas clandestinas en las que se tiraban los periódicos y que durante un breve período se comercializó de manera legal. Aquí se imprimían además folletines sindicales, documentos internos, comunicados, volantes, entre otros. Gran parte de estos se pueden encontrar en https://eltopoblindado.com/ agrupaciones/opm-marxistas/partido-revolucionario-de-los-trabajadores-prt.
} 
Al momento de interpretar las configuraciones sociales y espaciales en Argentina y Córdoba, este movimiento no es casual que parecía aproximarse a la noción de paisajes derivados de Milton Santos (Santos, en Zusman 2013). Expresión evidente de la forma particular en que la Argentina se insertaba al mundo desarrollado con su rasgo "periférico", respondiendo a intereses distantes cuya expresión eran las firmas multinacionales, Figura 5.

En su análisis del contexto nacional urbano y rural, hasta mediados de la década del ‘60, era el Norte, particularmente el monte o selva tucumana, donde el centro de las actividades del partido además de sindical, debía estar orientado a la acción insurreccional. Se indicaba que, mientras "para las masas empobrecidas del Norte la guerra revolucionaria es un problema inmediato, una necesidad...", en otras regiones y espacios, sean estos urbanos o rurales, no estaban dadas aun las condiciones materiales para la acción insurreccional.

Al respecto, la marcha de los acontecimientos se acentuó desde 1966. El año 1969, especialmente con el Cordobazo, significó un cambio en el balance realizado $y$, una

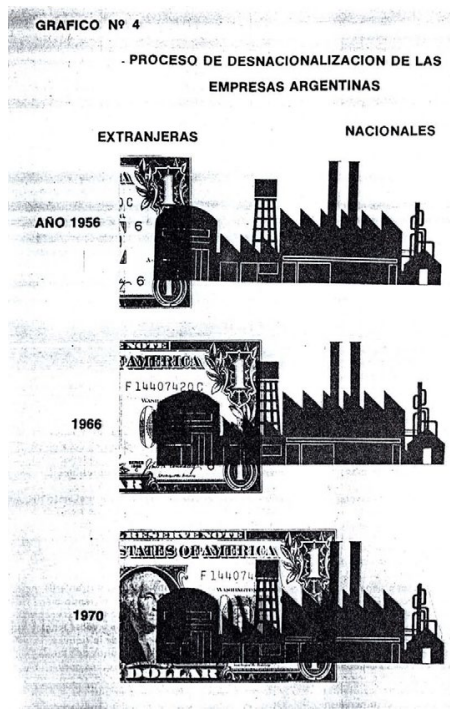

Figura. 5 Estrella Roja № 24 septiembre 1973 redefinición por parte del PRT de los procesos que se estaban dando en lo político, social y específicamente, en las interpretaciones de los espacios urbanos para la lucha revolucionaria ${ }^{13}$. Esta experiencia señalaba, por un lado, que el esfuerzo debía orientarse en encauzar las manifestaciones urbano populares -las cuales se consideraba aún con cierto grado de espontaneidad- hacia una insurgencia sostenida contra el sistema y la lucha por el poder. Al mismo tiempo, implicaba el desarrollo de una concepción de guerra de guerrillas que debía

\footnotetext{
${ }^{13}$ Entre éstas, las distintas sublevaciones obreras estudiantiles como el cordobazo, los rosariazos, el tucumanazo, el mendozazo, el cipollettazo.
} 
adaptarse a un contexto socio territorial diferente al de los principales referentes de la guerrilla -Mao, Guevara, Giap- dadas las características de un país con predominio obrero-urbano industrial. En este sentido, en 1970 se indicaba,

"si tenemos en cuenta que el sector de vanguardia de la clase está constituido por el proletariado industrial, que éste se concentra en Tucumán, Córdoba, Rosario y Buenos Aires, que su vanguardia es permeable a posiciones revolucionarias... éstas son las regiones donde fundamentalmente se desarrollará la lucha armada tanto en su forma rural como urbana. Esta situación de conjunto tiene un desarrollo particular en cada región. Dentro de este marco, el proletariado azucarero mantiene su puesto de vanguardia, pero con menos diferenciaciones con el resto que en años anteriores. ...

En las otras tres regiones, la lucha armada será urbana y suburbana, y tanto las acciones militares como las fuerzas armadas del partido desarrollarán niveles tácticos, operativos y estratégicos..." (PRT Resoluciones del V Congreso Julio 1970) ${ }^{14}$

Comparando la diferenciación espacial entre inicios de 1960 y el del año 70, se puede observar que el balance cambió considerablemente. La población de la ciudad de Córdoba había presenciado un marcado crecimiento pasando de 386.828 (1947) a 589.153 (1960) y 801.071 (1970). La instalación de las industrias automotrices multinacionales convertía a la ciudad en un centro industrial de relevancia y de "marcadas contradicciones". A su vez, en Córdoba, como en otras ciudades del interior del país, donde la presencia del aparato sindical tradicional -tildado de burocrático - tenía menos peso que en Buenos Aires, las manifestaciones y reclamos se expresaban con mayor virulencia y en conjunción con el activismo estudiantil.

\footnotetext{
${ }^{14}$ Para mayor profundidad ver PRT Resoluciones del V Congreso Julio 1970 pp 33-42.
} 
De esta manera, aparecía en los espacios urbanos un nuevo poder "el movimiento de masas". Este factor de poder se manifestaba en espacios materiales y simbólicos y con prácticas diferentes a las instituidas. De la mano de estas acciones urbanas, se señalaba que se inauguraba "un periodo de luchas populares que se caracterizarían crecientemente por un mayor nivel de conciencia política e ideológica sobre el régimen en su conjunto, y sobre los métodos y medios técnico-militares necesarios para enfrentarlo con éxito. ...", haciendo falta para esto la organización armada a través de un ejército revolucionario, Figura 6.

Desde ese momento se discutirá no solo sobre guerrilla rural, sino que se hace presente un nuevo término en el movimiento -guerrilla

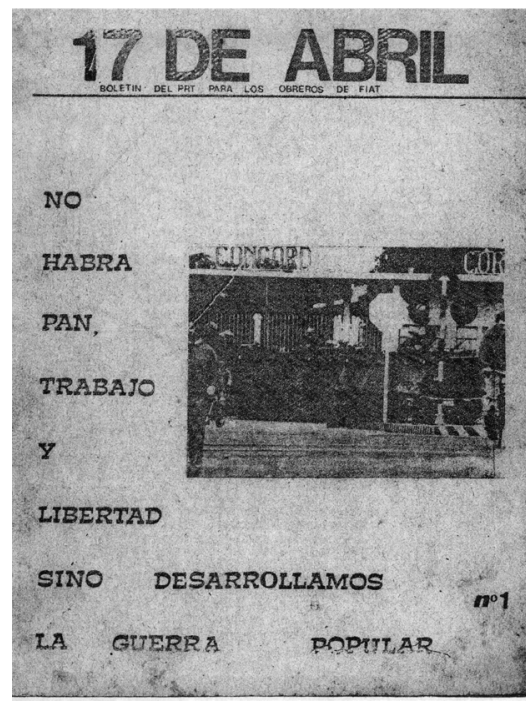

Figura 6. Boletín 17 de abril. Boletín del PRT para los obreros de Fiat. № 1 1971. (Sin fecha. Por su contenido puede corresponder a mayo de dicho año) urbana- para dar cuenta de una nueva práctica y un nuevo momento del equilibrio de fuerzas, debatiéndose fuertemente sobre el "problema de la relación campo ciudad" (PRT, Resoluciones del V Congreso, Julio 1970). Hacia 1971, las jornadas del Viborazo, nuevamente en Córdoba, indicaban al partido que "la existencia objetiva de la clase obrera urbana" del cinturón industrial, estaba siendo acompañada de "un grado mayor de conciencia", y por lo tanto se pasaba de una fase de "pasividad relativa de las masas al enfrentamiento abierto y combativo con el régimen" ${ }^{15}$, Figura 7. De aquí, por tanto, se incrementó la participación en distintos ámbitos fabriles, sindicales, barriales, estudiantiles y se multiplicaron las acciones.

\footnotetext{
${ }^{15}$ Estrella Roja № 31971
} 


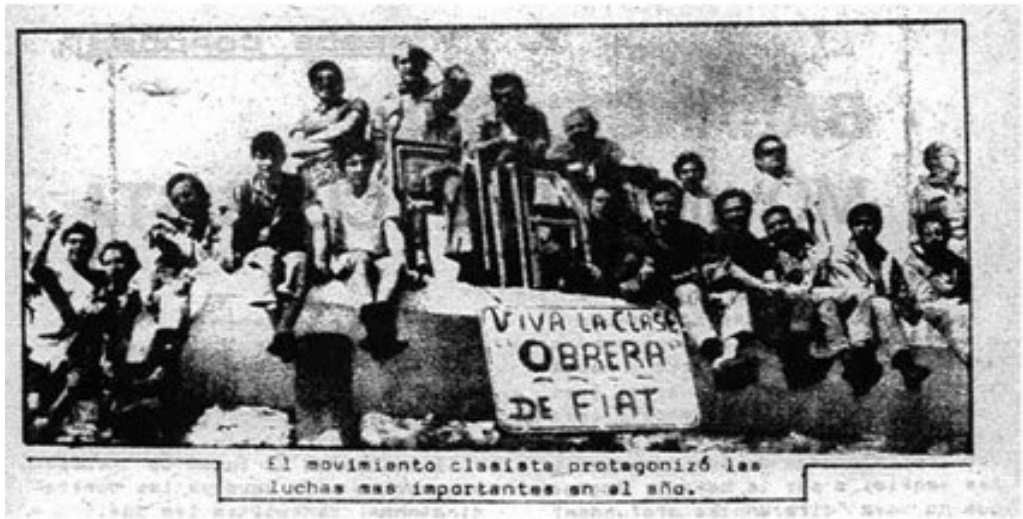

Desde Córdoba. Balance del movimiento clasista ${ }^{a} E l$ avance en la lucha de clases en nuestro pais agudiza las contradicciones, radicaliza las posiciones y lo que es más importante, pone al descubierto las ideas e influencias no proletarias; es en este marco que debemos ver, para comprenderlo, el proceso del movimiento clasista en Córdoba..."

El combatiente 1971 №65 pp.14-16

Figura 7. El combatiente 1971. №65 (recorte realizado por el autor del presente artículo)

De esta manera, se establecieron dos áreas estratégicas diferenciadas, donde la ciudad de Córdoba encontraba cierta centralidad, por el activismo fabril y estudiantil y por cuestiones de logística. Se configuraba un Norte obrero y campesino (TucumánSalta-Jujuy), donde se pretendía con el tiempo conformar un ejército regular, y un Centro y Sur obrero y popular (Córdoba, Rosario y Buenos Aires), donde se combinaban de manera no sencilla trabajo de base y sindical con guerrillas urbanas.

En pocas palabras, si bien encontramos una coincidencia entre Estado, empresas y diversos actores sociales -incluso aquellos que apelaban a la acción insurreccionalque sostenían un imaginario de ciudad industrial para Córdoba, no existía una interpretación única sobre el contenido de dicho paisaje y sobre la forma que debía adquirir hacia delante. 


\section{CONCLUSIONES}

El presente trabajo implicó una primera aproximación a las ausencias y presencias de la industria como motivo del paisaje para la ciudad de Córdoba. Se establecieron tres coyunturas claves en las que identificamos contrastes en las formas en que la relación industria y ciudad es presentada en el paisaje en Córdoba. El imaginario urbano que coloca a la industria como motivo del paisaje tiene antecedentes, pero se expresa sin ambigüedad en la década de 1950, según lo muestran los trabajos citados oportunamente. Este proceso se encuentra más analizado en relación con los imaginarios del progreso y modernización de las empresas multinacionales y del Estado.

Falta un mayor análisis de las prácticas de diversos actores que han contribuido a la construcción de la imagen de una Córdoba industrial, entre estas, diversas entidades empresarias, el sector de las pequeñas y medianas industrias, sindicatos y otras instituciones y organizaciones políticas. Estos a veces acompañaron y otras contradijeron las imágenes y sentidos de la ciudad que se pretendía enmarcar desde el Estado y el dinámico sector de la industria multinacional.

En términos de paisaje, las multinacionales fueron exitosas al colocar el motivo de "la vieja ciudad de provincia" en el imaginario de modernización y de ciudad industrial; sin embargo, parafraseando a Marx podemos señalar que el movimiento clasista no podía sacar de aquellos motivos del paisaje ni el ropaje ni las consignas para su praxis. En este sentido, no porque la imagen bucólica y tradicional del paisaje de Córdoba, había sido tensionada por las vanguardias estéticas, o acomodadas a la narrativa de las imágenes de modernización y progreso de las multinacionales -a través de Gacetika por ejemplo-; sino porque la tarea de disputar los sentidos desde dónde se construían las ideas de paisaje era un camino demasiado largo, estrecho, contradictorio y con más riesgo de caer en esteticismo e intelectualismo, que de permitir una mediación práctica que aproxime a la lucha política revolucionaria. Esto no impedía una imaginación geográfica emancipatoria, aunque no lo llamaran de esta manera.

Para cerrar las reflexiones, más allá de las tensiones presentadas, parece muy probable la hipótesis de que la huella trazada por el Estado y el sector dinámico industrial de la década de 1960 es la que permite aun hoy, con sus desplazamientos, 
el imaginario de una Córdoba industrial -en especial con la industria automotriz y autopartes- con suficiente potencia como para afectar las subjetividades, incluso ante el declive relativo de este sector frente a otros sectores de la economía cordobesa. Para estudiar esto, en el marco de la investigación, se están desarrollado entrevistas con actores vinculados con la actividad industrial en especial de foros productivos vinculados al sector de las pequeñas y medianas industrias en Córdoba, y analizando información documental de diverso tipo.

\section{Agradecimientos}

Se agradece a Ana Sofía Maizón y a M. Cristina Boixados por su gentileza y por el material de archivo de Ika. A Gabriela Cecchetto por su lectura y sugerencias referidos la industria automotriz en Córdoba. Al Archivo Histórico Municipal de Córdoba por su predisposición en este contexto de pandemia. Y a los evaluadores anónimos que con su lectura y comentarios colaboraron en precisar este escrito. Las debilidades presentes siguen siendo responsabilidad del autor.

\section{BIBLIOGRAFÍA}

Ansaldi, W. (2000). Una industrialización fallida: Córdoba 1880-1914, Córdoba: Ferreyra.

Astegiano, N. (2018). Circuitos espaciales de la producción de maquinaria agrícola en la Provincia de Córdoba. V Jornadas Nacionales de Investigación en Geografía Argentina. 16 y 19 de mayo 2018.CIG. UNICEN. Tandil.

Boixados, C. (2010). Las imágenes publicadas en los Álbumes del Centenario, Estudios Ibero- Americanos, 36, (1), 28-47, enero/junio,2010

Buffalo, L. (2013). Reestructuración productiva y configuración territorial: Pequeña industria metalmecánica en la Ciudad de Córdoba 2002-2012 [en línea]. Tesis de posgrado. Universidad Nacional de La Plata. Facultad de Humanidades y Ciencias de la Educación., Memoria Académica.

Búffalo L., Berti N., Tomadoni, C. (2009). Lógicas de configuración industrial: una propuesta teóricometodológica de análisis. El caso del sector metalmecánico en Córdoba, Argentina, Congreso XII encuentros de Geógrafos de América Latina. Montevideo Uruguay del 3 al 7 de abril.

Buffalo, L.; Carmona, Y.; Garcia, M. (2015). Reestructuración productiva en la Ciudad de Córdoba: transporte, logística y territorio. 
Cecchetto, G. (1988). Evolución de los asentamientos industriales IKA Y FIAT. Su inserción en el espacio urbano cordobés. Un estudio comparado (1955-1968). Informe inédito presentado al CONICOR. Córdoba, Argentina.

Cosgrove, D. (1998). Social Formation and Symbolic Landscape. 2o edition. Wisconsin: Univ. Press.

Cosgrove, D. (2008). Geography and Vision, Londres: I.B. Tauris.

Canclini, N. (2007). ¿Qué son los imaginarios urbanos y cómo actúan en la ciudad? Entrevista con A. Lindón. EURE, 33, (99), 89-99

De Santis, D. (comp.) (2004). A vencer o morir. Historia del PRT-ERP. Documentos, Buenos Aires: Nuestra América.

Driver F. (2013). Research in historical geography and in the history and philosophy of geography in the UK, 2001-2011: an overview, Journal of Historical Geography (42), 203-211

Gorelik, A. (2010). La grilla y el parque. Espacio público y cultura urbana en Buenos Aires, 1887-1936, Buenos Aires: Universidad Nacional de Quilmes.

Harvey, D. (1990). La condición de posmodernidad. Investigación sobre los orígenes del cambio cultura, Buenos Aires: Amorrortu.

Malecki, S. (2015). De la Córdoba de las campanas a la Córdoba de las avenidas. Transformaciones urbanas y nuevos imaginarios urbanos en Córdoba, 1947-1975, Caiana (6), 1ㅇs semestre 2015. Buenos Aires.

Margueliche, J. C. (2015). Memoria, identidad y representaciones sociales en el paisaje (pos) industrial. Tesis de Maestría en Paisaje Medio Ambiente y Ciudad. Facultad de Humanidades y Ciencias de la Educación. UNLP

Mitchell, D. (2008). New Axioms for Reading the Landscape: Paying Attention to Political Economy and Social Justice, En: Wescoat y Johnston, (eds). Places of Power: Economic and Political Driving Forces of Landscape Change. Springer Publishers

Mitchell, W.J.T. (2002). Landscape and power. The University of Chicago Press. Chicago.

Moyano, J. (2012). Política y sociedad en Córdoba. En: Cechetto y Zusman (comp.) La institucionalización de la geografía en córdoba. Contextos, instituciones, sujetos, prácticas y discursos (1878-1984), Córdoba: Editorial FFyH. UNC.

Navarro Floria, P. (comp.) (2007). Paisajes del progreso. La resignificación de la Patagonia Norte 18801916, Neuquén: Educo.

Pianetto, O. (2017). Sindicatos y política en Córdoba (1930-1943). En: Tcach C. (comp.) Córdoba bicentenaria. Claves de su historia contemporánea., Córdoba: Editorial Universidad Nacional de Córdoba.

Rocca, M. C. (2017). Arte, modernización y guerra fría. Las bienales de Córdoba en los sesenta, Córdoba: Editorial de la UNC. 
Silvestri, G. (2011.) El lugar común. Una historia de las figuras del paisaje en el Río de la Plata, Buenos Aires: Edhasa.

Silvestri, G. (2012). El color del río. Historia cultural del paisaje del Riachuelo. Buenos Aires: Universidad Nacional de Quilmes.

Tedesco, G. (2013). Fabricando autos y distinción... Imágenes de industria y ciudad en la Córdoba de los años '50 y '60. En Boixados (comp.) Maizón (colab.) Imágenes de ciudad. Representaciones y visibilidades de la vida urbana entre 1870 y 1970, Córdoba: Ferreyra.

Williams, R. (2001). El campo y la ciudad, Buenos Aires: Paidos.

Zusman, P. (2008). Perspectivas criticas del paisaje en la cultura contemporánea, En: J. Nogué (ed.) EI paisaje en la cultura contemporánea, Madrid: Biblioteca Nueva.

Zusman, P. (2013). La geografía histórica, la imaginación y los imaginarios geográficos, Norte Grande, (54), 51-66.

Wylie, J. (2007). Landscape, Routledg, Oxford.

\section{Otras Fuentes consultadas}

AHMC Archivo Histórico de la Municipalidad de Córdoba.

Capdevila, A. (1949). Córdoba Azul, Buenos Aires: Espasa Calpe.

Ceballos, A. (1897). Tierra Adentro. Sierras de Córdoba. Excursiones por los departamentos Anejos Norte, Punilla, Cruz del Eje y Minas. 1a edición, Buenos Aires: Cooperativa

Escobar Uribe, A. y Ellauri Obligado, G (1927). Álbum de la Provincia de Córdoba. Córdoba: La Elzeviriana.

Gacetika, Revista Kaiser Argentina. Varios Números.

Ika (1965). Ika. Diez Años. 1955-1965, Buenos Aires: Publicación de Industrias Kaiser Argentina.

Prt-Erp Documentos y publicaciones varias. En: https://eltopoblindado.com/agrupaciones/ opm-marxistas/partido-revolucionario-de-los-trabajadores-prt.

Río, M. y Achaval, L. (1905). Geografía de la Provincia de Córdoba., Buenos Aires: Compañía Sudamericana de Billetes de Banco.

Terzaga A. (1963). Geografía de Córdoba. Reseña física y humana. Córdoba: Assandri Ediciones. 


\section{EL AUTOR}

Santiago Llorens es Profesor en Geografía por el Instituto Antonio Sobral de la Provincia de Córdoba, Licenciado en Geografía por la Universidad Nacional de Catamarca. Ha realizado una Especialización en Epistemologías del Sur por el Consejo Latinoamericano de Ciencias Sociales, y en trayecto de Tesis en la Maestría en Antropología de la Universidad Nacional de Córdoba. Actualmente es Profesor Adjunto concursado de la cátedra Epistemología de la Geografía y Profesor Adjunto en la cátedra de Geografía Humana de la licenciatura en Geografía, Facultad de Filosofía y Humanidades, Universidad Nacional de Córdoba. Sus principales líneas de investigación se inscriben en la línea de Historia de la Geografía y la Geografía Histórica con especial interés en la producción y política del paisaje en contextos periféricos. Es director del proyecto de investigación "La construcción de la Geografía en Córdoba. Prácticas y discursos sobre el territorio provincial, 1890 - 2001" del Centro de investigaciones en Filosofía y Humanidades. Universidad Nacional de Córdoba y miembro del GIITT- Grupo de Investigación en Industria, territorio y trabajo-. Laboratorio de Estudios Territoriales. Facultad de Filosofía y Humanidades. Universidad Nacional de Córdoba.

sllorens@unc.edu.ar 